\title{
Desain Sepeda Kota dengan Konsep Folding Bike untuk Penyimpanan Ruang Terbatas dengan Pengguna Mobilitas Tinggi
}

\author{
Anisa Khoirun Nisa dan Bambang Iskandriawan \\ Departemen Desain Produk, Fakultas Teknik Sipil dan Perencanaan, Institut Teknologi Sepuluh \\ Nopember (ITS) \\ e-mail: iskandriawan10@yahoo.co.uk
}

\begin{abstract}
Abstrak-Transportasi sudah bergeser kearah gaya hidup dalam penggunaannya, hal tersebut terlihat pada aktivitas kegiatan sepeda saat ini yang hanya digunakan untuk kebutuhanjarak dekat, olahraga, berkumpul bersama teman dan keluarga atau dijadikan sebagai hobi dan sebagai media untuk mengembangkan minat dan pendekatan sosial. Hal tersebut dapat dilihat pada masyarakat terutama yang tinggal di kota besar yang didukung dengan adanya aktivitas dan kegiatan pendukung yang diadakan oleh pemerintah maupun instansi seperti lomba, sepeda santai, car free day. Tidak hanya itu program progam pemerintah yang mendukung peenggunaan sepeda, pengurangan polusi, dan kemacetan dengan dilihat dari perkembangan alat transportasi umum yang terus ditingkatkan dengan upaya agar masyarakat perkotaan yang memiliki aktifitas yang dinamis dapat beralih pada alat transportasi umum. Dengan upaya pemerintah tersebut maka perlu didukung dengan kebutuhan pengguna sepeda dalam menggunakan alat transportasi umum atau fasilitas umum lainnya.Dengan adanya fenomena dan potensi kedepannya maka dibutuhkan sepeda yang dapat menunjang aktifitas dan kebutuhan pengguna di perkotaan dengan aktifitas yang dinamis dan mobilitas tinggi. Sepeda tersebut harus memenuhi aspek kebutuhan pengguna seperti, Sepeda tersebut harus memenuhi aspek kebutuhan pengguna seperti, sepeda yang ringkas untuk dibawa dan dipindahkan dalam kendaraan umum atau kebutuhan lainnya, ringan untuk mempermudah pengguna dalam membawa, compact untuk mempermudah pengguna untuk memaksimalkan ruang terbatas. Dari ketiga konsep yang sesuai dengan kebutuhan pengguna maka ditemukan desain sepeda untuk diperkotaan dengan ruang penyimpanan terbatas untuk pengguna mobilitas tinggi.
\end{abstract}

Kata Kunci-Sepeda, perkotaan, mobilitas tinggi, ringkas, compact

\section{PENDAHULUAN}

$\mathrm{P}$ ERKEMBANGAN pengguna sepeda di perkotaan semakin meningkat, disebabkan oleh gaya hidup sehat, kesadaran terhadap lingkungan dan kondisi lingkungan diperkotaan yang menjadikan sepeda tidak hanya sebagai alat transportasi tetapi gaya hidup ini dapat menjadi alternatif solusi terhadap kebutuhan pengguna perkotaan [1].

Di perkotaan memiliki pertumbuhan penduduk yang semakin meningkat menyebabkan lahan dan ruang pada pemukiman, fasilitas publik terbatas dan dimanfaatkan maksimal, hal ini menjadikan perlu adanya sistem pada sepeda yang dapat mempermudah dalam ruang terbatas dan kebutuhan pengguna dalam menggunakan transportasi umum

Batasan masalah dari perancangan ini adalah :

1. Masyarakat perkotaan yang produktif dengan aktivitas yang banyak, dalam usia 25-40 tahun

2. Sepeda ini dapat dibawa masuk ke dalam fasilitas umum termasuk dalam angkutan umum perkotaan

3. Sepeda ini menggunakan sistem pelipatan yang memiliki pembaharuan dan efesiensi operasional

4. Sepeda ini menggunakan sistem pelipatan yang memiliki pembaharuan dan efesiensi operasional[2]

5. Menggunakan material dan bentuk yang disesuaikan dengan proses produksi bengkel yang ada pada UKM

Perancangan ini memiliki tujuan sebagai berikut :

1. Untuk mendapat sistem yang digunakan dari analisis dan aplikasi prototype agar sepeda dapat mudah ditarik dan kondisi terlipat

2. Menghasilkan desain sepeda yang dapat mudah dilipat dan ringkas pada saat dibawa dalam fasilitas umum maupun kendaraan

3. Menghasilkan desain sepeda yang dapat di produksi oleh UKM sepeda sesuai dengan keterbatasan UKM lokal untuk membantu menutupi masalah kebutuhan terhadap sepeda personal dalam masyarakat perkotaan

4. Menghasilkan desain sepeda yang dapat di produksi oleh UKM sepeda sesuai dengan keterbatasan UKM lokal untuk membantu menutupi masalah kebutuhan terhadap sepeda personal dalam masyarakat perkotaan.

Manfaat dalam perancangan ini tidak hanya timbul untuk user atau pengguna sepeda ini saja tetapi untuk UKM sepeda lokal sebagai sasaran produksi yang dituju [3];

A. Bagi User

1. Meningkatkan daya mobilitas yang efisien di perkotaan dengan alat transportasi yang ramah lingkungan.

2. Memiliki alat transportasi yang efisien dan fleksible

3. Memfasilitasi pengguna dengan kebutuhan sepeda yang lebih dari satu untuk aktifitas dan tempat yang berbedabeda.

4. Mempermudah pengguna dalam memilih jenis sepeda yang diinginkan sesuai kebutuhan 


\section{B. Bagi UKM}

1. Membantu dalam pengembangan UKM sepeda lokal, miputi dalam hal kebutuhan akan sepeda personal untuk membantu aktifitas masyarakat kota yang ada saat ini

2. Membuka lapangan pekerjaan baru.

3. Membantu agar hasil produksi kelas UKM dan bersaing dengan produsen besar lain dalam hal kualitas sehingga produksi UKM dapat menjadi alternatif dalam hal pengembangan dan produksi sepeda di Indonesia

Bagi Lingkungan: Dengan semakin banyak penggunaan diperkotaan maka berkurangnya tingkat polusi dan kedepannya akan mengungari kemacetan, tidak hanya itu akan meperluar dan memperbanyak komunitas sepeda di Indonesia.

\section{METODE PENELITIAN}

\section{A. Tahap Pengambilan Data}

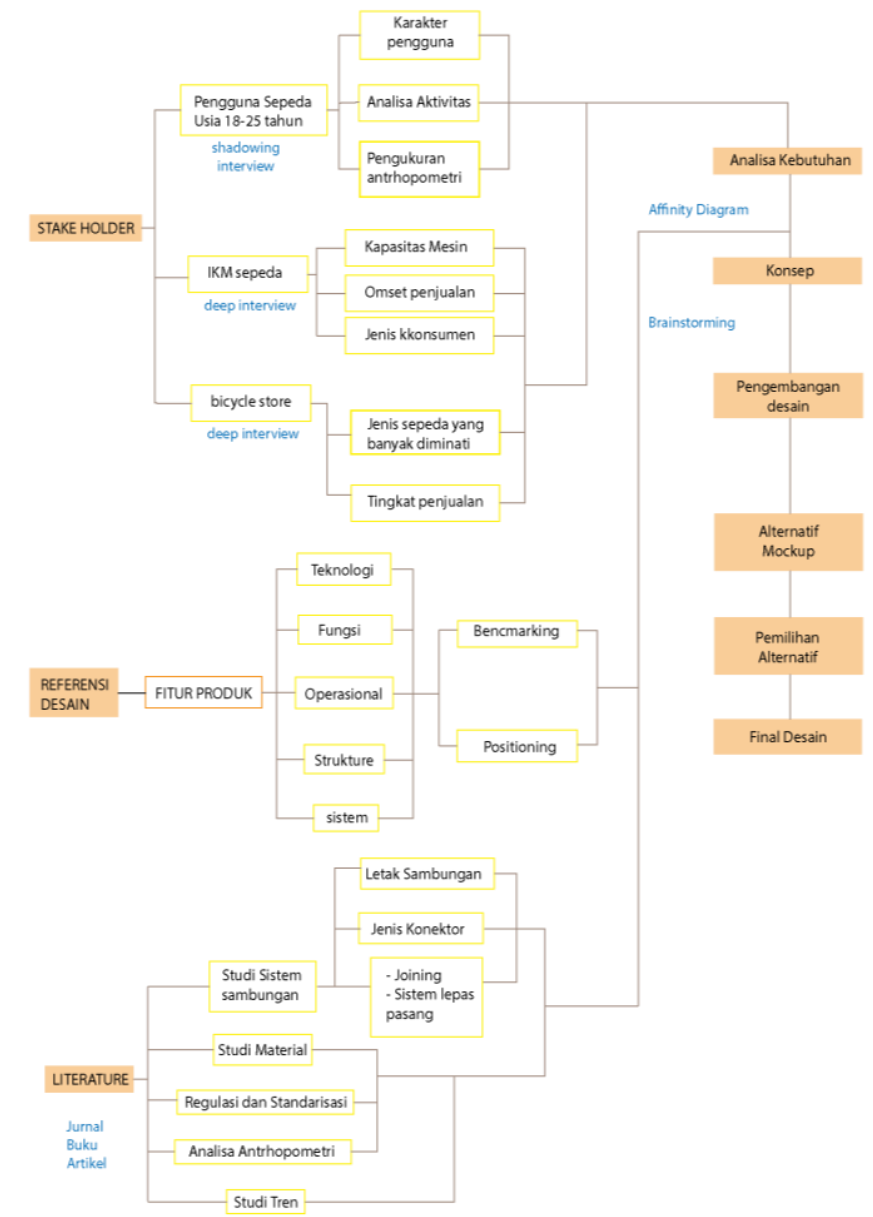

Gambar 1. Skema pengumpulan data.

Gambar 1. Menjelaskan tentang skema pengumpulan data dalam perancangan desain Sepeda berdasarkan analisis pengguna sepeda, digunakan beberapa metode dan proses dalam pengumpulan data. Dalam menemukan kebutuhan desain, pemecahan masalah, dan konsep desain hingga final desain dibutuhkan data data yang detail, original, dan akurat. Sumber data yang diperoleh dan dikelompokkan menjadi tiga yaitu stakeholder, studi literatur, dan referensi Desain.

\section{B. Tahap Studi dan analisis}

Tabel 1.

Analisis aktifitas pengguna

\begin{tabular}{c} 
Gambar \\
\hline \hline
\end{tabular}

Pada saat mengambil sepeda

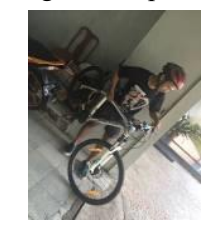

Aktivitas: mendorong sepeda sampai ke luar garasi menuju tempat yang lebih luas.

keluar garasi

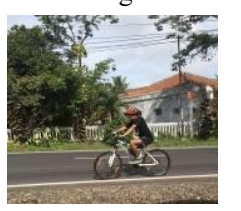

Aktivitas: bersepeda pada pagi hari, sekaligus berolahraga di sekitaran wilayah dan perumahan.

\section{Saat bersepeda}

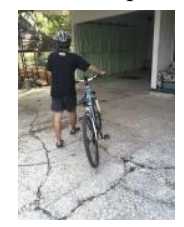

Mendorong

sepeda ke garasi

Aktivitas: setelah selesai bersepeda, lalu sepeda dimasukan kedalam garasi dengan didorong dari luar

Aktivitas ini dilakukan karena didalam garasi dipenuhi kendaraan lain, sehingga user kesulitan jika berhenti didalam.

Tabel 2.
Analisis permasalahan desain
Keterangan
$\begin{gathered}\text { Kondisi tempat penyimpanan dua } \\ \text { sepeda dan bergabung dengan sepeda } \\ \text { motor dan mobil, akses keluar masuk } \\ \text { yang tidak mudah dan fleksible } \\ \text { (membutuhkan waktu yang lebih lama } \\ \text { untuk mengeluarkan sepeda). } \\ \text { Sepeda juga disimpan didepan pintu } \\ \text { belakang rumah sehingga akses keluar } \\ \text { masuk pun sulit. }\end{gathered}$
$\begin{aligned} & \text { Tempat penyimpanan yang kedua ini } \\ & \text { lebih tertata, dan memiliki ruang sendiri } \\ & \text { untuk sepeda. Tempat ini didesain } \\ & \text { hanya untuk dua sepeda, akses keluar } \\ & \text { masuk pun mudah karena tidak } \\ & \text { digabungkan dengan barang atau } \\ & \text { kendaraan lain. } \\ & \text { Tidak hanya itu, sepeda dibuat } \\ & \text { penyangga yang dibuat sendiri agar } \\ & \text { sepeda tetap stabil }\end{aligned}$
sempat penyimpanan




\section{Analisis User}

Analisis psikografi bertujuan untuk mengetahui kebutuhan dan karakter pengguna sehingga produk yang dirancang sesuai dengan target pengguna, dan produk perancangan dapat sesuai dengan lingkungan [4].

Demografi Konsumen

$$
\text { Usia : 25-30 tahun }
$$

Jenis Kelamin: Laki-laki

Pekerjaan : Karyawan / Pekerja

Aktifitas : Berkumpul dengan teman, bekerja, olahraga, bertemu rekan bisnis, berdiskusi, berkumpul, berpetualang.

Interest

: Kesehatan, sepeda, kekeluargaan, sadar akan barang yang bagus, hal yang baru, sesuai tren yang ada.

Opinion : Nilai fungsi dan kegunaan, Style Tertarik hal yang baru, Tidak terlalu memperhatikan harga

Need : Produk yang mengikuti tren dan lifestyle saat ini, Harga sesuai kualitas, Minim perawatan, Produk yang sesuai dengan berbagai macam aktivitas user

\section{Analisis Geometri}

Data analisis geometri ini digunakan sebagai acuan dan standar untuk menentukan nilai dan geometri sepeda yang akan di desain.

Tabel 3.

Referensi analisis geometri

\begin{tabular}{clc}
\hline \hline \multirow{2}{*}{ CODE } & \multicolumn{1}{c}{ KETERANGAN } & COMMUTING \\
CITY
\end{tabular}

Data analisis ini sebagai referensi geometri sepeda yang akan di desain dengan proses pencarian menggunakan metode pengukuran gambar berskala meliputi objek yang digunakan yaitu sepeda lipat eksisting dan sepeda kota eksisting [5].

Tabel 4.

Analisis geometri

\begin{tabular}{cllllllll}
\hline \hline ANALISIS & A & B & C & D & E & F & H & K \\
\hline \multirow{2}{*}{ referensi } & $400-$ & $72.5^{\circ}$ & $100-$ & $70^{\circ}$ & $540-$ & $280-$ & $440-$ & $1050-$ \\
& 620 & $75.5^{\circ}$ & 150 & $72.5^{\circ}$ & 620 & 290 & 450 & 1100 \\
Analisis 1 & 559 & $72^{\circ}$ & 150 & $72^{\circ}$ & 559 & 286 & 443 & 1061 \\
Analisis 2 & 584 & $73^{\circ}$ & 144 & $72^{\circ}$ & 612 & 289 & 448 & 1100 \\
Analisis 3 & 431 & $75^{\circ}$ & 118 & $70^{\circ}$ & 596 & 289 & 445 & 1071 \\
Analisis 4 & 590 & $72.5^{\circ}$ & 132 & $71^{\circ}$ & 558 & 280 & 441 & 1076 \\
\hline \hline
\end{tabular}

metode pengukuran gambar berskala meliputi objek yang digunakan yaitu sepeda lipat eksisting dan sepeda kota eksisting. maka hasil tersebut digunakn kembali untuk penyaringan data melalui metode populasi, yaitu nilai yang diambil merupakan nilai terbanyak atau 2-3 angka yang berdekatan dari uji coba tersebut. angka yang akan digunakan merupakan angka median dari beberapa nilai uji coba.

Tabel 5.

Hasil analisis geometri

\begin{tabular}{cllllllll}
\hline \hline Analisis & A & B & C & D & E & F & H & K \\
\hline & 584 & $72^{\circ}$ & 150 & $72^{\circ}$ & 559 & 289 & 443 & 1071 \\
& 590 & $72.5^{\circ}$ & 144 & $72^{\circ}$ & 558 & 289 & 441 & 1076 \\
Fix & 584 & $72.2^{\circ}$ & 147 & $72^{\circ}$ & 558 & 289 & 442 & 1073 \\
\hline \hline
\end{tabular}

\section{E. Analisis Bentuk}

Analisis bentuk ini berdasarkan dari prediksi tren sepeda tahun 2017, dilansir dari (bikeradar.com)salah satu perkembangan sepeda yang ada bahwa dalam satu sepeda memiliki multi-fungsi, tidak hanya itu desain minimalis dan sedikit polesan warna cerah akan menjadi tren tampilan sepeda di tahun mendatang sesuai dengan Gambar 2.

Dari hal tersebut maka didapat desain sepeda yang akan diacu pada bagian framenya, sehingga didapat garis dan bentuk untuk dikembangkan dalam brainstorming ide dan desain.

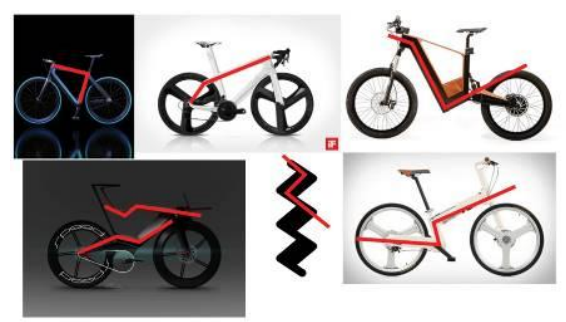

Gambar 2. Analisis Bentuk.
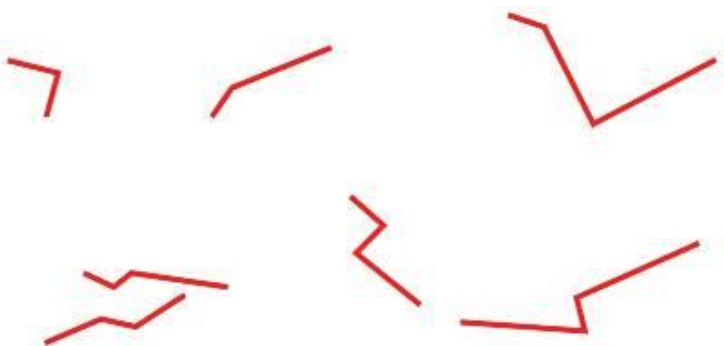

Gambar 3. Analisis Bentuk.

Gambar 3 dihasilkan garis dan bidang dari acuan frame, dari beberapa frame yang dianalisis hasilnya adalah kebanyakan menggunakan garis geometri, Dari garis yang ada diatas maka ini menjadi dasar dan acuan untuk brainstorming ide dan dalam mendesain.

\section{1) Preliminary Desain}

Tabel 6.

Alternatif desain

\begin{tabular}{cccc}
\hline \hline Parameter & Alternatif 1 & Alternatif 2 & Alternatif 3 \\
\hline Keamanan & 2 & 4 & 3 \\
Styling & 3 & 3 & 2 \\
Bobot sepeda & 4 & 11 & 7 \\
TOTAL & 9 & 3 & 2 \\
\hline \hline
\end{tabular}


Tabel 7.

Parameter alternatif desain

\begin{tabular}{|c|c|c|c|c|}
\hline Parameter & Indikator & Alt 1 & Alt 2 & Alt 3 \\
\hline Keamanan & $\begin{array}{l}\text { Dilihat dari } \\
\text { bentuk,ukura } \\
\text { n, kekuatan } \\
\text { dari sistem } \\
\text { sambungan } \\
\text { tersebut }\end{array}$ & $\begin{array}{l}\text { plat dengan } \\
\text { volume } \\
80 \times 80 \times 80 \\
(\mathrm{~mm})\end{array}$ & $\begin{array}{l}\text { Pipa dengan } \\
\text { diameter } \\
32 \mathrm{~mm}, \\
\text { tinggi } \\
100 \mathrm{~mm}\end{array}$ & $\begin{array}{l}\text { Plat dengan } \\
\text { volume } \\
80 \times 80 \times 180 \\
(\mathrm{~mm})\end{array}$ \\
\hline Styling & $\begin{array}{l}\text { Dilihat dari } \\
\text { bentuk,ukura } \\
\mathrm{n}, \text { kekuatan } \\
\text { dari sistem } \\
\text { sambungan } \\
\text { tersebut }\end{array}$ & $\begin{array}{l}\text { tujuh } \\
\text { responden }\end{array}$ & $\begin{array}{l}\text { Delapan } \\
\text { responden }\end{array}$ & $\begin{array}{l}\text { lima } \\
\text { responden }\end{array}$ \\
\hline \multirow[t]{10}{*}{ Bobot sepeda } & Dilihat dari & d. $40 \mathrm{~mm}$ & d. $40 \mathrm{~mm}$ & d. $40 \mathrm{~mm}$ \\
\hline & material yang & $\rightarrow 136 \mathrm{~mm}$ & $\rightarrow 136 \mathrm{~mm}$ & $\rightarrow 136 \mathrm{~mm}$ \\
\hline & $\begin{array}{l}\text { digunakan } \\
\text { nda frame }\end{array}$ & d. $30 \mathrm{~mm}$ & d. $30 \mathrm{~mm}$ & d. $30 \mathrm{~mm}$ \\
\hline & & $\rightarrow 660 \times 2=1$ & $\rightarrow 660 \times 2=$ & $\rightarrow 660 \times 2=$ \\
\hline & & $320 \mathrm{~mm}$ & $1320 \mathrm{~mm}$ & $1320 \mathrm{~mm}$ \\
\hline & & d. $32 \mathrm{~mm}$ & plat600x15 & plat $600 \times 15$ \\
\hline & & $\rightarrow 150 \times 2=$ & $0(\mathrm{~mm}) \times 2$ & $0(\mathrm{~mm}) \times 2$ \\
\hline & & $1080 \mathrm{~mm}$ & d. $32 \mathrm{~mm}$ & d. $32 \mathrm{~mm}$ \\
\hline & & d. $32 \mathrm{~mm}$ & $\rightarrow 1080$ & $\rightarrow 1080$ \\
\hline & & $\rightarrow 100 \mathrm{~mm}$ & $\begin{array}{c}\text { d. } 32 \mathrm{~mm} \rightarrow \\
100 \mathrm{~mm}\end{array}$ & $\begin{array}{c}\text { d. } 32 \mathrm{~mm} \rightarrow \\
100 \mathrm{~mm}\end{array}$ \\
\hline
\end{tabular}

\section{KONSEP DAN PEMBAHASAN}

\section{A. Konsep Desain}

Setelah melakukan analisis aktifitas dan permasalahan maka didapat beberapa kebutuhan pengguna dan kata kunci yang akan merujuk pada konsep desain.

Penyimpanan ruang terbatas $\rightarrow$ desain harus dapat memenuhi permasalahan ruang yang terbatas dengan cara memaksimalkan dimensi dan volume sepeda.

Menunjang aktifitas pengguna aktifitas mobilitas tinggi $\rightarrow$ merancang desain yang dapat menunjang aktifitas luar seperti penggunaan sepeda dalam alat transportasi umum sehingga sepeda yang dirancang harus mudah dalam operasional membawa maupun operasional melipat

Konsep desain dalam perancangan berasal dari permasalahan yang ada di lingkungan kemudian menjadi kebutuhan pengguna. Dari beberapa anilisis yang telah dilakukan, maka didapatkan konsep perancangan sebagai berikut :
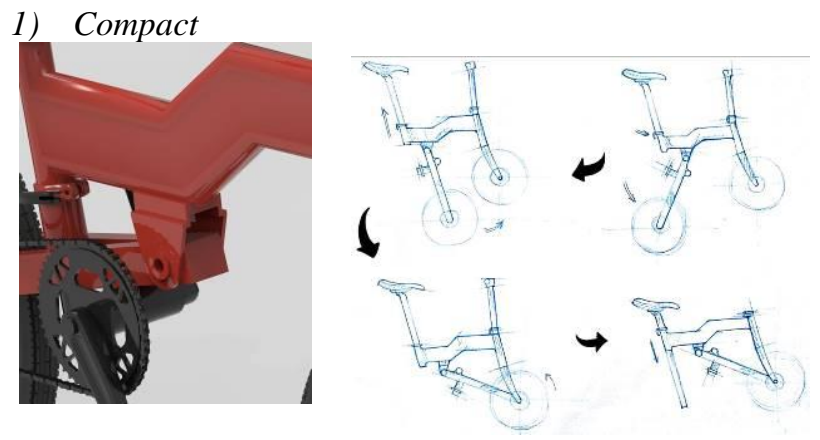

Gambar 4. Sistem Pelipatan

\section{2) Portable}

Tabel 8. Proses menarik sepeda

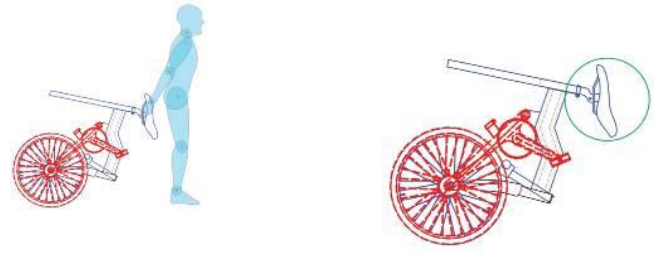

Alternatif 1

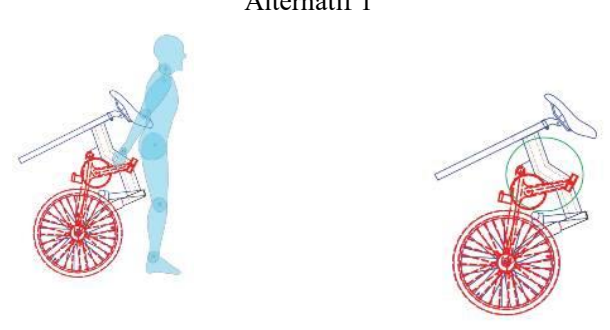

Alternatif 2

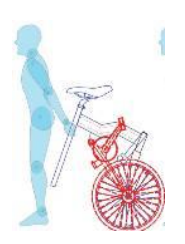

Alternatif 3

\section{B. Tahap Produksi}

Tahap produksi meliputi :

1. Persiapan Material

Mempersiapkan material yang dibutuhkan dalam pembuatan rangka, mengukur dimensi pipa, dan ketebalan plat yang di butuhkan

2. Pembuatan sistem

Memastikan terlebih dahulu analissi sistem pelipatan yang digunakan sudah benar dan dapat diaplikasikan dalam bentuk prototype

3. Pembuatan Rangka

Membuat rangka sepeda dari material yang sudah disiapkan dengan menggunakan analisis geometri yang sudah dilakukan

4. Uji Coba Sistem

Mengaplikasikan sistem yang sudah terhubung dengan rangka sehingga dapat dilihat titik salahnya di bagian mana

\section{Perakitan}

Setelah semua part sudah ada, rangka dan sistem sudah benar maka dilakukan perakitan

\section{Finishing}

Tahap ini meliputi tahap pewarnaan rangka sesuai dengan analisis branding yang telah dilakukan 

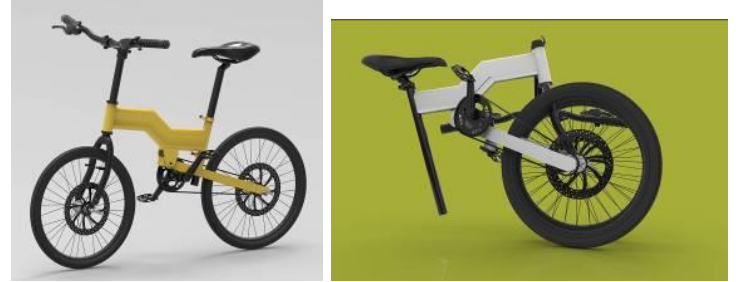

Gambar 5. sepeda kondisi normal dan terlipat.

\section{KESIMPULAN DAN SARAN}

Desain yang dihasilkan adalah sepeda dengan sistem lipat dalam bentuk rotasi putar dengan basis sepeda kota. Sepeda ini diperuntukan untuk pengguna perkotaan yang memiliki aktifitas dan kebutuhan yang dinamis, dengan pemenuhan kebutuhan pengguna dengan ruang penyimpanan terbatas.

1. Target user sepeda kota ini adalah masyarakat perkotaan yang produktif dengan aktivitas yang banyak, dalam usia 25-40 tahun

2. Dimensi sepeda saat dalam kondisi normal $1400 \times 750 \mathrm{~mm}$ dan kondisi terlipat $750 \times 750 \mathrm{~mm}$

3. Material yang digunakan disesuaikan kemampuan dan alat yang sesuai dengan UKM yaitu besi hitam

4. Warna yang digunakan yaitu kuning dan hitam. Warna ini dipilih karena beberapa aspek yaitu user dan tren warna.

5. Proses membawa sepeda yaitu ditarik disamping user, dan ditarik pada bagian sadel sepeda.

Beberapa saran untuk perancangan sepeda ini untuk disempurnakan agar kekurangan yang sebelumnya dapat diperbaiki oleh perancangan selanjutnya, seperti:

- Memperbaiki sistem rem dengan menggunakan rem yang tanpa kabel atau penempatan kabel yang lebih tertata sehingga pada saat pelipatan tidak teranggu oleh kabel rem.

- Memperbaiki sistem pelipatan terutama pada bagian hub depan dan bagian belakang yang masih belum sejajar dengan cara melihat perhitungan posisi sistem lipat yang tepat yang terdapat pada Gambar7.

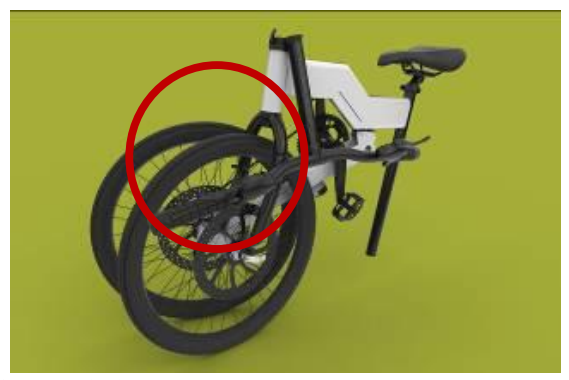

Gambar 6. titik antar $h u b$.
- Mengubah gear dari single sebagai salah satu alternatif penggunaan pengguna dengan kebutuhan tertentu.

- Memperbaiki sistem folding pada bagian headtube agar lebih stabil dan kuat dengan penguncian ganda seperti pada sistem folding yang sudah ada pada sepeda eksisting saat ini.

- Mengubah ukuran rim sebagai salah satu alternatif penggunaan jarak jauh dengan menggunakan rim yang lebih besar dibanding sebelumnya

- Memperbaiki bentuk dan sistem seattube dan seatpost pada kondisi terlipat sehingga bagian tersebut tetap aman dan tiak ada bagian yang masih terhunus sesuai dengan Gambar8.

Gambar 7. seatpost yang terhunus.

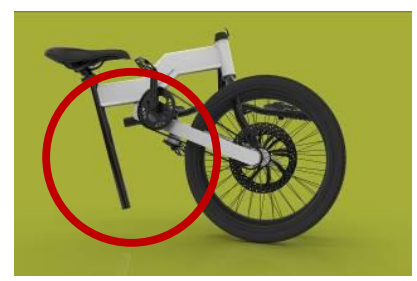

\section{DAFTAR PUSTAKA}

[1]. Kurniawan, D, Tritiyono, B. Desain Sepeda Kampus Sebagai Sarana Penunjang Mobilitas Mahasiswa di Dalam Kampus, Studi Kasus : Institut Teknologi Sepuluh Nopember.

[2]. Iskandriawan, B., Jatmiko, Ustazah, E.N., Hawari, F., Tandem Bike Design for Apartment Residents as An Idea to Reduce Air Pollution. MATEC Web of Conferences 101, 03017, DOI: 10.1051/matecconf/201710103017. 2017.

[3]. Saloka, LA,. Pengembangan Desain City Bike Denganmesin Elektrik Sebagai Sarana Penunjang Aktivitas Remaja Di Perkotaan Yang Dapat Diproduksi Ukm Lokal. 2015.

[4]. Iskandriawan, B., Split Air Conditioning Selection of Apartment Unit around Jabodetabek Area to Enhance COP. International Journal of Applied Engineering Research. Vol. 9, No. 19, pp.6277-6290. 2014.

[5]. Iskandriawan, B., Jatmiko, The Development of Bicycle into Trandem: The Bike Can be used as Tandem or Single Depend of The Necessity. Applied Mechanics and Material. Vol. 607, pp.920-925. 2014. 